Canadian University Music Review

Canadian University Music Review

Revue de musique des universités canadiennes

\title{
Expecting Surprise Again: Neil Young and the Dialogic Theory of Genre
}

\section{William Echard}

Volume 22, numéro 2, 2002

URI : https://id.erudit.org/iderudit/1014505ar

DOI : https://doi.org/10.7202/1014505ar

Aller au sommaire du numéro

\section{Éditeur(s)}

Canadian University Music Society / Société de musique des universités canadiennes

ISSN

0710-0353 (imprimé)

2291-2436 (numérique)

Découvrir la revue

Citer cet article

Echard, W. (2002). Expecting Surprise Again: Neil Young and the Dialogic Theory of Genre. Canadian University Music Review / Revue de musique des universités canadiennes, 22(2), 30-47. https://doi.org/10.7202/1014505ar
Résumé de l'article

Cet article poursuit un double objectif : i) formuler une théorie dialogique du genre et de la référence stylistique qui soit particulièrement, mais non exclusivement, destinée à la musique rock; et ii) offrir, à l'égard de la musique de Neil Young, une lecture détaillée du jeu sur le genre et d'aspects qui lui sont associés, comme l'instabilité, l'authenticité et l'imprévisibilité. Par cette approche, les auteurs, les interprètes, les styles et les genres deviennent tous diverses formes de personnages. Il est ainsi possible d'élaborer une analyse complètement dialogique de leurs relations et interpénétrations.
All Rights Reserved ( C Canadian University Music Society / Société de musique des universités canadiennes, 2003
Ce document est protégé par la loi sur le droit d'auteur. L'utilisation des services d'Érudit (y compris la reproduction) est assujettie à sa politique d'utilisation que vous pouvez consulter en ligne.

https://apropos.erudit.org/fr/usagers/politique-dutilisation/ 


\section{EXPECTING SURPRISE AGAIN: NEIL YOUNG AND THE DIALOGIC THEORY OF GENRE}

\section{William Echard}

Since the late 1960s, Neil Young has been one of the central figures in rock music. His work has been both commercially successful and widely influential on other musicians, including many of the present generation. His longevity and noteworthiness stem from a number of factors, but one of the most important is the manner in which he has frequently managed to surprise listeners. Even a cursory reading of the rock press or a brief stay in the Internet Neil Young discussion group reveals the crucial importance of concepts like "surprise" and "unpredictability" in Neil Young reception. ${ }^{1}$ In one sense, this is to be expected, for reasons that will be summarized early in this paper. However, it may be suggested that the stylistic range of Young's work is not quite as great as its reception may tend to suggest. There is still some question as to why themes of surprise and unpredictability are so central to Neil Young reception, when in fact his work does not stray very far from rock music and very closely related genres.

Investigating this question can not only help illuminate unique features of Neil Young's work, but can also tell us something about the nature of genre boundaries in rock music more generally. This paper develops the outline of a dialogic theory of genre, and then analyzes Neil Young's unique stylistic profile with respect to this model, and also with respect to the general nature of rock ideology of the 1960s and 1970s. While Neil Young forms the specific case study, the dialogic theory of genre broached here, and the general issues of genre raised by Young's work, are applicable to a wide range of artists.

We can begin with a recent passage from a prominent rock critic:

Throughout his long, near thirty-year career, [Neil] Young has defied categorization; his songwriting has ricocheted from the personal to the political, from the straightforward to the obtuse. Dipping into almost every musical genre (rock, pop, soul, country, folk, jazz, blues, rockabilly, punk, technopop, grunge), rather than merely "do" a certain kind of music, Young has grabbed it, shaken it upside down and turned it into his own unique style-sometimes with uneven results. Throughout, Young has committed himself to stretching limits, taking risks. The result: Unlike any other artist, Young has traveled the

1 This present paper relies upon many generalizations about trends and themes in Neil Young reception history. These generalizations are based on extensive research into music press materials and discussion among fans on the Internet, reported in detail in William Echard, "Neil Young, Embodiment. and Stylistic Diversity" (Ph.D. diss., Department of Music, York University, 2000). 
often treacherous road from the Sixties to the Nineties without ramming into a dead end, arriving battle-scarred but vibrant, with a compelling body of work. ${ }^{2}$

This is a fine example and summary of the way fans and critics often assess Young's relationship to genre boundaries. The relationship is a double one. It includes a tendency to veer between extremes, but also the retrospective judgement that this has, taken on the whole, been an artistic strength. The same tendencies, however, can lead critics to opposite conclusions. Consider the following comments made by Dave Marsh:

Spend a couple of weeks really saturated in Young's work up to Rust Never Sleeps, ${ }^{3}$ and you'll come to the same conclusion [I did]: he's less diverse than erratic, his stylistic charms the result of lack of commitment rather than successful eclecticism ... In the end, reconciling Young's rock 'n' roll with his spineless country-pop proved impossible - and not only for me, since the man himself has never been able to combine the two into anything convincing ... Young lacks the coherent, consistent world view that marks the greatest artists, in rock or anywhere else. ${ }^{4}$

The unusual career trajectory followed by Neil Young is well known. 5 In the mid-1960s, he was ambitious but ambivalent, both courting and rejecting stardom. In the late 1960s and into the 1970s, he achieved commercial success on a number of fronts: with the garage rock of Crazy Horse, the country rock of the Stray Gators, and with Crosby Stills Nash and Young (hereafter CSNY). The mid-1970s brought the notorious dark period, in which he abandoned his commercially-viable country rock style and for a number of years presented only abrasive, pessimistic work, both on record and in concert. By the late 1970s, assisted by a return to more accessible styles, his place in the emerging rock canon was very nearly a matter of consensus among critics and fans. Young's high status at this time is exemplified in the feature article written by John Rockwell for the New York Times:

Along with Bob Dylan, Neil Young is probably the most important rock composer and performer North America has produced ... [Neil Young's Decade $^{6}$ ] is a compilation far removed from the commercial cynicism behind most "greatest hits" packages. It's really a carefully chosen retrospective,

2Holly George-Warren, "Introduction," in Neil Young: The Rolling Stone Files (New York: Hyperion, 1994), 4.

3Reprise 2295, July 1979.

4Dave Marsh. "Album Review: Tonight's the Night," in Neil Young: The Rolling Stone Files, 135-37. Review originally published in 1975.

5 The details of Neil Young's career have been well-documented in numerous other sources. For an excellent history of his early career, see John Einarson, Don't Be Denied (Kingston: Quarry Press, 1992). Although somewhat stilted by the author's personal perspective, the best overview of Young's entire career is Jimmy McDonough, Shakey (Toronto: Random House, 2002). Fairly reliable and undeniably extensive information about discography, tour dates, and other such material can be found at the largest of the unofficial Neil Young web sites, www.hyperrust.org.

6Reprise 3RS 2257. November 1977. 
designed to stake Mr. Young's claim as one of the most moving and important artists in the history of rock. That claim is well worth staking.

Immediately after this stunning consolidation came the 1980s genre experiments, taxing the patience and good faith of nearly all fans and critics. During the period, Young not only presented wildly differing musical styles in rapid succession (for example Electro Pop on Trans, ${ }^{8}$ Rockabilly on Everybody's Rockin', 9 and country on Old Ways ${ }^{10}$ ), but he also performed through the mediation of a number of clearly fictitious personas. And then, after his acceptance among fans and critics had perhaps reached a career low, there was another period of consolidation in the 1990s, continuing into the early 2000 s. During this latest phase of his career, there has been a significant shift in Neil Young's personal image. While he had often been described, since the 1960 s, as a loner, vulnerable, and sensitive, in the 1990s he was more frequently portrayed as a figure of control and powerful self-determination. As Eric Weisbard noted in 1995, "It's getting harder and harder to remember that, for much of his career, Neil Young has been regarded-if loved-as a self-destructive oddball."11

An impressive range of genres was touched upon during this journey: singer-songwriter, traditional folk, several kinds of country music, psychedelic garage rock, adult contemporary, symphonic rock, and some other genres in smaller doses, including blues, electro pop, rockabilly, electro-acoustic composition, and punk. It is this combination of a mercurial career path and an exceptionally wide of range of genre experiments that has led to the kind of critical disagreement evident between George-Warren and Marsh.

Evidently, Neil Young has arrived at a complex position, by a complex path. This is one reason that he has been frequently perceived as surprising and unpredictable. However, complexity in itself does not necessarily produce surprise. An artist could maintain these kinds of contradictions in a stable form, displaying richness but not change. The Grateful Dead did that for long stretches of their career, and one may suggest that a contemporary provocateur like Eminem does it as well. We could even suggest that since the 1990s, Neil Young has done likewise. So we can ask: what mechanisms earlier in Young's career caused the tensions and contradictions in his work to achieve the extra feature of surprise? A number of factors could be drawn into this discussion: his restless personality; an abiding lyrical interest in instability and liminality; a tendency to design projects which are narrowly focused, and therefore strongly contrasting; and frequent divergences from established practices of career timing. Especially interesting, though, is the manner in which Neil Young has been positioned relative to the very nature of genre boundaries in

7 John Rockwell, "Will Neil Young Join Dylan in Rock's Pantheon?" New York Times, 27 November 1977 , sec. $2,1,13$.

8 Geffen 2018, January 1983.

9 Geffen 4013, August 1983.

10 Geffen 24068, August 1985.

11 Eric Weisbard, "Not Fade Away," Spin (September 1995) [pages unknown]. Interview found at http://mbl.musicblvd.com/cgi-bin/tw/907116842016355_105_2746 (February 1998). 
rock, his basic stance with respect to territories of sameness and difference. It is this aspect of his work that I would like to consider in depth. In order to do so, it is first necessary to present an outline theory of genre. The theory is far from complete, but is designed to highlight the features of genre which are most relevant to the formation of personas and to issues of authorial integrity.

Boundaries between genres are both permeable and perspectivally specific. Any two listeners or critics will often display striking differences between their concepts of how a particular genre should be defined, and which artists should be included. Genres also change frequently, and indeed it is part of their function to provide a basis from which to innovate and test boundaries. ${ }^{12}$ However, despite this fluidity, genres play a powerful role in the structuring of musical practices, providing a shared set of coordinates and a sense of stability. In all social practices, there is a fluid and reciprocal relationship between forces of stasis and forces of change, and in turn between individual subjects and the cultural fields in which they improvise their identities. For the present analysis of Neil Young, we can begin by noting that the construction and use of genres is one key site in which this relationship of structuration between individuals and fields can be seen to work in musical cultures.

In a similar vein, Robert Walser has borrowed Bakhtin's formulation of genre as a horizon of expectations brought by interpreters to a text. This formulation takes into account both the structured, shared nature of genres, and their mode of existence as a mobile frame of reference. ${ }^{13}$ Such an approach to genre, rooted in practice theory and dialogism, is especially appropriate to the study of Neil Young, as the rest of this paper will demonstrate. Besides highlighting the dual face of genres-fluid and stable, collective and individual-a dialogic theory can emphasize the importance of personal perspective and identity without collapsing into an atomistic view of the subject. Identity is relevant not only because genres are the locus of so much social and emotional investment. Identity is also important because genres themselves have identities and social lives. They have histories, personalities, and almost seem to exert a form of agency in the way they sometimes constrain and guide social actors. ${ }^{14}$

The personality of any given genre comes in part from its prior associations: with people, histories, places, and ideas. This is true not just of genres, but of any recognizable feature in a piece of music. Even novel features will have

12Throughout this paper, my principal source for genre theory is Ingrid Monson, Saying Something: Jazz Improvisation and Interaction (Chicago: University of Chicago Press, 1996). My general approach is also strongly influenced by both Simon Frith, Performing Rites: On the Value of Popular Music (Cambridge: Harvard University Press, 1996), Chapter 4, and Roy Shuker, Understanding Popular Music (London: Routledge, 1994), 145-47.

13Robert Walser, Running With the Devil: Power, Gender, and Madness in Heavy Metal Music (Hanover: Wesleyan University Press, 1993), 27.

14 In using the term "social life" in this way, to refer to the sort of agency demonstrated by a social construct such as genre, I am influence by Arjun Appadurai, "Introduction: Commodities and the Politics of Value," in The Social Life of Things: Commodities in Cultural Perspective (Cambridge: Cambridge University Press, 1986), 3-63, and also by the manner in which works of art are often cast as "a peculiar kind of subject" in European aesthetic theory since the $18^{\text {th }}$ century (see Terry Eagleton, The Ideology of the Aesthetic [Oxford: Basil Blackwell Press, 1990], 4). 
strong connotations. Because of this, each element in a piece of music carries its own cluster of voices, a kind of autonomous persona, and the piece of music as a whole becomes a dialogue between these voices. This is all to say that any musical utterance is in fact intermusical. This perspective has been developed in detail by Monson:

I develop the idea of intermusicality ... as a way to begin thinking about the particular ways in which music and, more generally, sound itself can refer to the past and offer social commentary. In so doing, I am interested in how music functions in a relational or discursive rather than an absolute manner ... The topic of interest here is the musical quotation or allusion, which embodies the conflict between innovation and tradition in jazz performance as well as the larger question of how instrumental music conveys cultural meaning. ${ }^{15}$

In order to apply this mode of analysis to Neil Young, it is necessary to go beyond processes like quotation and allusion, and to discuss more subtle degrees of reference. It is also important to note that the voices identified as active under the dialogic viewpoint are not just stylistic references, but also political and social actors of a sort. An advantage of the dialogic perspective is that it does not require us to separate or choose between the formal structure of a text and its social life, but rather highlights the manner in which formal features of a text embody social histories and interactions, and also in which social practices acquire and deploy relatively stable textual signifiers.

For example, when Neil Young in 1987 first dressed in a fedora and sunglasses in order to perform stage-band blues with The Bluenotes, he was activating a complex of voices and references from the past and from other generic identities. In this case, there is a tension between the seeming irony and even campiness of the mobilization of familiar signifiers, and Young's complex, previously existing relationship to the blues. On the one hand, some commentators suggest that Young's relative lack of connection to the blues, and to African-American musical styles in general, has been a distinguishing feature of his persona. ${ }^{16}$ Certainly, there aren't many outright blues forms to be found in Young's earlier catalogue, and those which do exist tend to be fairly obscure (for example "Vampire Blues"). There is another sense, though, in which Young has been tangentially connected to the blues throughout his career. In a review of a Bluenotes concert, David Fricke makes the connection explicit by suggesting that the Bluenotes' music was "blues in the great Young tradition-songs of tortured self-examination and love gone all wrong emphasized by his poignant vocals and brilliant ice-pick guitar."17 The suggestion here is that while the bulk of Young's work is far distant from the blues in terms of formal textual features, there is an affective alliance at play. The same interpretive move has been made at various other points in Young's career, for

15Monson, Saying Something, 97.

16See for example David Downing, A Dreamer of Pictures (New York: Da Capo, 1995), 51-52.

17David Fricke, "Neil Young and the Bluenotes," Melody Maker, 30 April 1988, 20. Concert review. 
example when a reviewer of Harvest suggested that the more repetitive elements of Young's country-rock style may be his own "equivalent of the 12-bar blues,"18 or when Young himself noted that both Mike Bloomfield and Paul Butterfield told him he would be a "natural" at playing and singing the blues. ${ }^{19}$ The suggestion may be strengthened by noting Young's occasional use of the word "blues" in the titles of songs which are formally not blues, as in "Ambulance Blues" and "Revolution Blues" (both from On the Beach, ${ }^{20}$ also containing "Vampire Blues"). Young's own view of This Note's for You ${ }^{21}$ may perhaps be taken as a summary: "I don't really think it's blues. It's blue ... Three of the songs have a late-night, torch song kind of thing. You know, the club's empty kind of feeling." 22

Surprisingly, no commentators have said much about the political implications of this sort of genre play. To what degree does "not blues" translate as "not black?" In other words, should we read Young's non-blues blues moves as a kind of affective alliance, or as a sort of appropriation, one more move in the general removal of African American influences from late 1960s and early 1970s rock styles? To what degree does Young's reduction of "blues" to basically two moods-either up tempo swing numbers or down tempo "empty bar" music-reduce a complex musical form to a series of stereotypes, and in turn help to obscure the racial and political stakes of the genre? Of course, by the late 1980s the "blackness" of blues music was much less of an issue than it had been in the late 1960s. However, perhaps that is in itself a social fact which requires explanation. We could ask whether Young's work was complicit in the very depoliticization of the blues which now seems to provide a justification for that work. The issue is complicated, and I am not aiming to provide a conclusion or definitive judgement. However, I do wish to highlight the fact that Young's seemingly simple use of "blues" signifiers helps to create texts which are dialogic in a political as well as a formal capacity, creating a situation which is intermusical in the sense described by Monson, who continues:

When jazz musicians learn traditional repertory, quote a particular musician's solo, play a tune with a particular groove, or imitate a particular player's sound, they reveal themselves to be very aware of musical history. It is important to note that the sonic features that allude to prior musical performances include dimensions beyond harmony, rhythm, and melody. The use of a plunger mute by a trumpet player, for example, can invoke the legacy of Cootie Williams and Bubber Miley. ${ }^{23}$

18 Peter Knobler, "Harvest," Crawdaddy, 30 April 1972, 14. Album review.

19Mark Rowland, “Cruise Control: Neil Young's Lonesome Drive," Musician (June 1988): 63-74. Interview.

20 Reprise R 2180, July 1974.

21 Reprise 25719, April 1988. This album is the primary example of Young's stage band blues work with the Bluenotes.

22John Einarson, "Neil Young: The Dawn of Power Swing," Canadian Musician (August 1988): 50-54. Interview.

23 Ibid., 97. 
Monson is writing about jazz: a genre in which such references are often deliberate, and in which audience members sometimes exert a high level of sensitivity and knowledge in finding them. This is the paradigm case of intermusicality, where the players and listeners are very aware of the process. It should be noted, though, that intermusicality can also function below the level of direct awareness. In assessing Neil Young's complex relationship to genre boundaries, it will be important to discuss the possibility that the alterity set up by unexpected stylistic voices may not always be recognized as such. In other words, intermusicality may exist on a continuum, with deliberate and clearly-recognized cases at one extreme, and with more unconscious or deliberately masked instances on the other. While the former kind of intermusicality is clearly important in some phases of Young's career-during all the times in which he was flagrantly indulging in genre play, and during which fans and critics tended to question the authenticity of his persona - the latter kind is also crucial, because it can help explain why Neil Young can be perceived as somewhat unstable or edgy even in cases where he is not, on the surface, playing with genre boundaries. These points will be clarified further as the study progresses.

Monson acknowledges that intermusicality is an extension of Kristeva's concept of intertextuality. While she does not discuss Kristeva's work to any extent, it is worth noting that there is an important link between the manner in which Monson uses the concept and Kristeva's original formulation. For Kristeva, intertextuality is not a simple relation of quotation or allusion between texts in a formal sense, but rather a fundamental process of the unconscious, by which the transposition of an utterance from one text to another, or from one signifying system to another, produces a corresponding shift in the enunciatory position of the speaking subject. ${ }^{24}$ For this reason, intertextuality has a strong effect on the formation of subjects and identities, and is in this sense involved in the formation of both the agency of genres, and the agency of musicians and listeners as well. Monson does not develop the idea along these psychoanalytic lines, but she achieves a similar result by developing the link between intermusicality and Bakhtin's model of centripetal and centrifugal forces:

The diversity of language styles [Bakhtin] called heteroglossia, and the tensions between an overarching category (music, in our case) and the particularity of social styles (jazz, R\&B, classical, rock and roll) he called respectively centripetal and centrifugal forces of language. On the centripetal side are forces of centralization, unification, authoritativeness (hegemony), and standardization; on the centrifugal are those of decentralization, disunity, and competition among multiple social voices. Bakhtin sees these forces intersecting in any particular speech utterance, which has aspects that affirm the general category and those that are highly particular to the moment. ${ }^{25}$

24 Julia Kristeva, Revolution in Poetic Language (excerpts), in The Kristeva Reader (New York: Columbia University Press, 1986), 111.

25Monson, Saying Something, 99. 
For the purpose of discussing Neil Young, the only thing I would change about this formulation is to emphasize the nested nature of the hierarchy. In the case of Neil Young, it makes more sense to cast rock as the overarching category, exerting a centripetal pull on its various subgenres, and to cast the subgenres-for example punk, rockabilly, country, and blues-as the particular, destabilizing forces. In general, any given generic voice is not inherently centripetal or centrifugal. It will function in one way or the other depending upon context, and as we will see, the ability of any given genre to exert either a centripetal or centrifugal force, or both at the same time, is a key element in Neil Young's unique approach to style and persona.

The term which summarizes this perspective, synthesizing the idea of intermusicality with the model of centripetal and centrifugal forces, is dialogism:

It is Bakhtin's idea of dialogism - that categories are "contradiction-ridden, tension-filled," unstable entities caught between the general and the wholly specific - that I wish to underscore in approaching the problem of boundaries, both in music and in the broader culture. The idea that the centripetal and centrifugal are dependent upon each other for their mutual definition in ways that vary over time is an important part of the story. ${ }^{26}$

No genre, authorial persona, or piece of music can exist without reanimating all of the voices implicit in its raw material, and in turn activating the play of centripetal and centrifugal forces implicit in those voices. So music is always a kind of dialogue. This viewpoint can be extended to include the persona of the musician. The creative persona is also plural: possessing a uniqueness and a kind of singularity, but one made up of a dialogue between many other voices. In a situation like this, there are no completely stable or fully defined genres or authorial personas. However, there is often the desire for stability and identity, and there are social interests and forces which work to construct these.

Under this view, one way of characterizing Neil Young surprises would be to say that these are moments where intermusicality is highlighted. Not every utterance draws attention to its own intermusicality. In order to create the impression of a strong authorial presence, the inherent multivocality of the utterance is sometimes obscured. The centrifugal potential of multivocality can be damaging to the impression of a strong authorial persona, which requires that everything point back to itself, centripetally. In much of Neil Young's work, however, attention is drawn to the play of voices within the work, and to the centrifugal potential implicit in every utterance. The impression of a single, coherent author is allowed to weaken, as we can see in the many instances where unexpected stylistic changes were met with the complaint that this was not the real Neil Young, or that Young had lost his way, or that he was burying his true self under constructed personas and genre experiments. From a dialogic point of view, there is no charade, or lack, or loss of direction here, 
but rather a clear presentation of the multiplicity that is always lurking under the surface of every utterance.

That might not be quite the right way to say it, though. Putting it that way almost makes Neil Young sound postmodern, and in the end I will argue instead that he is an arch-modernist in a sense typical of 1960s rock ideology. When in 1983 Neil Young suddenly dressed and sang like a rockabilly artist, for example, previous assumptions about his persona were shaken by the force of this other voice. And yet, this moment occurred as part of an utterance made by Neil Young himself, and so a play of alterity and assimilation was set up. When we look at Neil Young reception in the long term, we see that very often this kind of surprise is re-absorbed into a newly stabilized persona. After a while, intermusicality was no longer a destabilizing factor, but became a fixed part of Neil Young. He was expected to surprise, and-his stylistic diversity was taken as a mark of authorial integrity.

There are numerous examples of critics and fans making such interpretive moves, so I will only cite a few. In the first, we see the manner in which the abrasive, pessimistic, and unpolished aspects of Young's mid-1970s work were reinterpreted as a form of heroism. Ironically, this passage was written by Dave Marsh, about 20 years earlier than the excerpt quoted earlier:

Tonight's the Night ${ }^{27}$ finds Neil Young on his knees at the top of the heap, struggling to get back to his feet ... The music has a feeling of offhand, first-take crudity matched recently only by Blood on the Tracks. It's almost as though Young wanted us to miss the album's ultimate majesty in order to emphasize its ragged edge of desolation ... If the songs here aren't pretty, they are tough and powerful, with a metallic guitar sound more akin to the abrasiveness of the Rolling Stones than the placid harmonies of CSNY. The melodies haven't disappeared (as they seemed to on On the Beach), but they are only sketched in, hints of what they could be. There is no sense of retreat, no apology, no excuses offered and no quarter given. If anything, these are the old ideas with a new sense of aggressiveness. The jitteriness of the music, its sloppy, unarranged (but decidedly structured) feeling is clearly calculated. The music draws us in ... and here is where it is new-it also spits us back out again, makes us look at the ugliness on the surface and beneath it ... Crying over the death of his real and imagined friends, Neil Young seems at once heroic and mock heroic, brave and absurd. He leaves us as he found us, ravaged but rocking. ${ }^{28}$

In general, rock critics were almost unanimous in agreeing with this point of view. There were, however, a few dissenting voices:

Last summer I was amazed at some of my friends, who stood in wonderment at the "tremendous courage" Young displayed in "confronting the abyss" in Tonight's the Night. It was another stupid stumble-bummer, rendered partic-

27Reprise MS 2221. June 1975.

28Dave Marsh, "Album Review: Tonight's the Night," in Neil Young: The Rolling Stone Files, 135-37. 
ularly ridiculous by lyrics that were sloppy and idiotic beyond the call of duty (early in the morning 'bout the break of day / He used to sleep until the afternoon-I mean, what a harrowing lifestyle) and pure stretches of professional patheticness so ostentatious it became its own brand of creepy narcissism..$^{29}$

Here we see a dynamic similar to that between George-Warren and the later Marsh. One critic chooses to recast the disruptive event as a strength, and in effect to restabilize Neil Young as a figure of authorial integrity. Another critic emphasizes, if not exactly intermusicality itself, then the continuing destabilizing effect that intermusicality and plurality of persona have had on Neil Young. As a rule, though, the former strategy was the more common one, and has been seen at other points in Young's career as well; for example in the reception of Trans, and Old Ways, in which clearly intermusical and personadestabilizing stylistic decisions were often interpreted as just another facet of Young's rock auteurship:

"Well, Mr. Weird is at it again" was one of the first reactions I heard to the synthesized sounds and Vocoderized vocals that typify [Trans]. With Young, one learns to expect the unexpected, but this record is as drastic a break from career form as David Bowie's kiss-off to his Thin White Duke persona with Low. And twice as surprising, too, because Young, despite his penchant for shifting gears from record to record, has always sunk his roots deep into the good earth, the fertile loam, of the American singer/songwriter tradition ... [But on Trans], it's as if by abstracting human intelligence from the emotional biases that often misdirect it, we can attain a truer ideal of perfection-electronically ... [The] incongruity between old and new modes on Trans is striking - sort of like seeing a satellite dish sitting outside a log cabin ... It's the world in transition (hence the title?), a unique moment in human history in which old technologies are yielding to new ones-and where human values struggle to maintain an equilibrium with the accelerated change ... Neil Young is really still a sweep-hand clock in a digital world, a solitary quester after truth. ${ }^{30}$

[A] brief description of the basic musical constituency of Old Ways might suggest a snug wallowing in the conservative traditions of $C \& W$, but this would deny the dark, brooding sense of mischief that informs songs like the volatile "Are There Any More Real Cowboys?" and the imperative "Get Back to the Country," both of which marry a deep sense of satire with an unfailing accuracy of form ... Conventions exist only for Neil Young to destroy them ... For all its surface charm and eternal country swing, this is a bitterly ironic, violently hilarious record, full of scathing sarcasm ... It's amazing, really: after all these years, after all these traumas and fears ... Neil Young is still ferociously in command. Massively unfashionable as this record will seem to today's young haircuts, it nevertheless provides conclusive proof that Neil Young is still keeping jive alive. ${ }^{31}$ 
Reactions of this sort nicely display the fine balance between centripetal and centrifugal forces in Young's work, and the manner in which, for the most part, critics have tended to emphasize and reinscribe the centripetal ones. More will be said about this shortly. For now, we can note that the trend in Neil Young reception seems to be that intermusicality has broken out strongly at certain points, disrupting established views about who Neil Young was and what he would do. But there was also usually an effort made by listeners and critics to somehow to assimilate these events into the locus of their pre-formed understanding of Neil Young. The attempt to "make sense" of these events is in cases like this equivalent to a reimposition of the monologic perspective, a deepening or elaboration of the pre-existing Neil Young persona, rather than its dissolution.

The analysis above is focused on the level of Neil Young's individual persona. Before returning to this perspective in more depth, we should also consider the more general nature of rock music as a genre, and Neil Young's place in this larger field. To begin, we can examine the relationship between rock, as the central construct in a field of centripetal forces, and its various subgenres, which at certain times may function as destabilizing factors.

Closeness and distance between genres are changeable and relative quantities. However, certain genres share special kinships. For example, there is a cluster of genres which I will call the genre family of rock. This family includes antecedent musics such as $R \& B$ and country, as well as the many subgenres that at any given time form the unmarked core of the family, and also decedents like punk. ${ }^{32}$ Some factors that can draw genres into such a family relationship include hybridization, historical lineages, and formal or functional similarity. These are all centripetal forces which can allow an umbrella genre such as rock to exist, and to incorporate many subgenres into itself. By "incorporate into," I mean in part that when elements of a subsumed subgenre are used in a piece of music, they do not seriously threaten the categorization of that piece as a member of the larger family. More specifically, the subgenres are represented or understood as components of the larger family, and not as autonomous centers of their own. But while centripetal forces hold genres together, there are always centrifugal forces pulling in the other direction. Part of the reason for this lies in intermusicality. Each of the subgenres subsumed under rock, and pointing towards it as a center, are also relatively autonomous, with different histories and other possibilities, and consequently with a tendency to draw towards other centers. Country music, for example, can be made to seem part of rock music, but it is also a relatively autonomous genre of its own. The presence of country within rock is perched between the centripetal force of the

32The concept of unmarked core is a problematic one, since every genre displays a variety of specific incarnations, and sometimes these compete for recognition as the "true" representative of the genre overall, as in East-coast and West-coast hip hop in the mid-1990s. Nevertheless, there is an important sense in which some musics will be unproblematically accepted as solidly and clearly part of a particular genre, especially when compared to other musics which can not even be considered as candidates for centrality. 
rock family, and the centrifugal force exerted by other views of country, in which it is not part of rock.

To come back to Neil Young, we can argue that the strong country inflections evident in his early work-for example "The Losing End" on Everybody Knows This Is Nowhere, ${ }^{33}$ or the cover version of "Oh Lonesome Me" on After the Gold Rush, ${ }^{34}$ and even the pedal steel guitar throughout Harvest ${ }^{35}$ and the fact that the album was recorded in Nashville-are generally counterbalanced by the overall image presented by Neil Young at the time, and also by the other kinds of material on the record. Textually, the country references did not predominate, and in terms of persona, there were still more "rock star" components to Neil Young than there were country clichés. It was not generally surprising to fans and critics that Young should display a relationship to country music in this way, and the lack of surprise rests partly with the fact that the potentially centrifugal force of country music was being held in check, insofar as the bulk of textual and contextual features framing these country moves were linked to the California rock counterculture, and the folk-rock and garage styles of music. For example, while a song like "The Losing End" is very strong in its country inflections, the songs from Everybody Knows This Is Nowhere that tended to draw more attention were the long garage jams ("Down by the River" and "Cowgirl in the Sand"), and the pop-rock "Cinnamon Girl." In this case, Neil Young could use country elements without anyone suggesting that he had ceased to be a rock musician.

As with Young's use of the blues, discussed earlier, the process of keeping country references in check is not politically neutral. Fairly or not, country music in the late 1960s tended to be associated with political and social conservatism of a sort disagreeable to the California rock counterculture from which Young first emerged. Young would frequently toy with the boundaries of countercultural ideology, for example when he said the following in a 1970 interview: "[If there's a revolution], I'll be in Big Sur with my guns ... I'll get a big cannon if they're gonna have a revolution. I'll sit up on top of my studio there with my material gains after the game, and, uh, contemplate my future." 36 At that time, Young's careful treatment of country generic signifiers could be seen as a part of his management of an insider-outsider relationship to hippie ideology more generally. The fact that most rock fans and critics seemed unsurprised by Young's country moves might be taken to suggest that he managed this balance successfully.

By contrast, many commentators were surprised when Neil Young presented unadulterated country music in the 1980s. Country music had been a part of Neil Young from the start, and it did not always threaten the stability of his persona. This point was made at the time by a few critics, for example Christgau, who wrote: "Warners is touting Old Ways as [Neil Young's] country

33 Reprise RS 6349, May 1969.

34Reprise RS 6383, September 1970.

35Reprise MS 2032, February 1972.

36Elliot Blinder, "Neil Young Q \& A," in Neil Young: The Rolling Stone Files, 45-54. Interview originally printed in 1970. 
move ... [But] Neil has been making country moves ever since he put 'Oh Lonesome Me' on After the Gold Rush." 37 Nonetheless, many fans and a significant number of critics chose instead to see the album as surprising and unexpected. Country music was not a new element in Young's work: but a change in emphasis, or timing, or context, can lead to a situation in which certain elements seem suddenly ready to fly away from the category of which they have always been a part. The centrifugal potential of country was actualized in this case. And again, there is an interesting correlation between the stylistic features of Young's 1980 s country music and his social positioning of the time. Not only did his work during this period use a far greater number of "country" signifiers, alongside a relative disuse of his established 1960s and 1970 s rock style, but Young also chose to publically announce his political support of Ronald Reagan. It should not be suggested that this linkage of intensified country style with intensified right wing politics is "natural," but rather that Young's decision to mobilize both of them simultaneously tended to play into established generic stereotypes, and therefore to emphasize centripetal rather than centrifugal forces (and in particular, flipped the balance between the competing centripetal forces of rock and country as they had been established in Young's earlier work).

Each of Young's 1980s genre experiments can be read in this way: as a surprisingly direct statement of a style which was always present in Young's work, but not usually foregrounded or left without counterbalances. With the possible exception of electro-pop, and to a slightly lesser degree rockabilly, in none of these cases was a major new stylistic element added. ${ }^{38}$ Rather, it was the case that the centrifugal elements present in his work all along became actual rather than latent. As noted earlier, the concept of latency in this case does not mean that the intertextual tensions do not have any effects at all. The richness of a text like Everybody Knows This Is Nowhere derives partly from the play of centrifugal and centripetal forces, even if that play of forces is latent in the sense of not provoking a crisis of genre attribution, or in the coherence of the authorial persona. As has been suggested in the readings of blues and country clichés offered earlier, latency may often be a sign of a social power negotiation or even repression, mostly suppressed or closely managed but still able to inject considerable energy into the reception of a work.

This line of analysis can lead us back to one of the central questions stated at the outset of the paper, helping to explain why Neil Young can be surprising, and can seemingly move outside of his pre-established generic profile, without in the end being anything but a rock musician. The key to being surprising, while nonetheless remaining within a single genre, is to find the centrifugal forces implicit in that genre. A genre like country or rockabilly is admitted to

37Robert Christgau, "Close Enough for Nashville," The Village Voice, 24 September 1985, 77. Album review.

38Even rockabilly and electro pop were not entirely unprecedented. Although these genres, in their stereotypical forms, were absent from Young's earlier work, he had from the outset established a clear interest in both technological experimentation and roots musics. So while these genres were formally incongruous, they were not entirely foreign to the spirit of his pre-existing work. 
the rock family for historical and stylistic reasons, but from the perspective of rock they are captive genres, to the point that their presence is often masked altogether. If you emphasize them enough, you can seem to be moving beyond the stylistic envelope of rock music. But from another perspective, it would be more accurate to suggest that you are simply drawing attention to the centrifugal forces that gave rock its identity in the first instance.

How is it that a genre family like rock can both contain and not contain particular sub-genres? Why do genres like country and pop exist as insideroutsiders to rock? One important factor lies in the manner in which genres compete with and supplant one another over time. At any given historical moment, within a large genre family, the member genres will have differing status, depending partly on their place in the history of the family. Some will constitute, for that moment, the unmarked core. Others will be ancestors, and for that reason marginalized. We can use the term supplanted family members to refer to marginalized ancestors. Other subgenres will be newly emerging as destabilizing factors, working to change the genre from within. These subgenres are often supplanters, turning the central subgenres into dated ancestors. Interestingly, Neil Young does not display a consistent pattern of identifying with either marginalized or central subgenres. And when identifying with marginalized subgenres, he splits his time between the supplanters and the supplanted. His punk and electro pop moves, for example, can be seen as siding with supplanters, but his roughly contemporaneous rockabilly phase was a vote for the supplanted. Over the course of his career, Neil Young has aligned himself with both the past and the future of rock music, and in this way is constantly repositioned at the center.

The manner in which Neil Young plays with these possibilities has given him a distinctive kind of persona. This persona is simultaneously mobile and stable, and with respect to rock music broadly defined, simultaneously critical and celebratory. Neil Young pushes the tensions and contradictions of rock from the inside, but in the end always proselytizes for the aesthetic and social virtues of the genre. This puts Neil Young in sharp contrast with artists like Roger Waters or Frank Zappa, who have also launched internal critiques of rock, but without the corresponding return to celebration. Neil Young questions rock in a manner which ultimately reaffirms its core myths, and during both the late 1970s and early 1990s-the periods following his two great phases of genre experimentation-Neil Young fully embraced the role of rock icon. The timing of these career resurgences is interesting in that it corresponds to two periods in which the "death of rock" was being declared with special intensity by some critics and academics.

According to a common narrative, the rock era "is a period that starts with the emergence of rock ' $n$ ' roll in the middle of the 1950s and which then 'progresses' through various significant moments or stages until it ends with punk rock in the 1970s." ${ }^{39}$ Negus points out that there have been two general threads running through "death of rock" narratives, which almost always argue 
that rock's demise began in the early 1970s, and was completed from within by punk. ${ }^{40}$ One thread is economic, suggesting that although the music industry was for a time centered on rock music, this was a passing situation. The other thread is ideological, suggesting that rock culture encapsulated certain values and beliefs, which by the late 1970 s no longer appeared viable. In this connection, Negus cites Frith as having identified...

three distinct aspects of the ideology of rock. First, the notion of the rock "career" [as a process of learning a craft, refining skills, and paying dues]. Second, rock was viewed both as a complex art form and as an expression of specific generational sentiments and feelings. Such beliefs were informed by ideas derived from a romantic aesthetic. Third, appreciation of rock music was informed by the belief in an integral link between performers and audiences and the idea of the "rock community."41

We have seen that all three of these factors are central to Neil Young reception, and while his boundary-crossing has led Young to problematize many specific features of the rock industry and style, he has never thrown these central ideological claims into question. ${ }^{42}$ Indeed, his unexpected decisions usually give the impression of having been taken precisely to reassert core rock values. Frequently, then, Neil Young troubles superficial aspects of rock culture in order to realign himself with more fundamental concerns. This observation can help us to understand why Young has survived through many stylistic periods, both in terms of changes in his own work and in the prevailing popular music contexts, from the 1960s to the early 2000s. If, however, Neil Young survives by highlighting the difference between local stylistic features and the overarching framework of rock ideology, and if his integrity has been consistently rooted in that overarching framework, then should it not be the case that his continued relevance is profoundly threatened, or even already gone, if in fact rock ideology is becoming outmoded? Are the fans and critics who still find importance in Young's work fooling themselves? Negus, for one, might not think so. He points out that new artists and genres with a clear alignment to rock ideology continue to emerge, and continue to find audiences:

In the case of rock, I would suggest that rumours of its death have been greatly exaggerated and that many people have been communing with the spirit of rock since 1976. The idea of a "rock era" is based on a particular experience of rock (biographical, geographical, generational, and social) which fails to allow for how musical forms are transformed and move on in different ways across the planet, acquiring new significance in different situations and as part of other dialogues ... [Such movements] indicate that rock has been alive and living, but within the musical dialogues of different generations. For many of

40 Ibid., $147-49$.

41 Ibid., 149.

42Frith's third factor, the integral link between performer and audience, has not been directly addressed in this paper. It is implicit, however, in my analysis of the critical tendency to reposition disturbances to Neil Young's identity as a form of authorial integrity. This strategy could be seen as evidence of the desire for an authentic persona with which to share the kind of link described by Frith. 
these musicians and audiences rock has been experienced as part of a different history, one that doesn't necessarily "begin" with a revolutionary moment during the middle of the $1950 \mathrm{~s}^{43}$

Neil Young, then, questions 1960s rock culture in a manner which nonetheless reanimates its core ideologies. This has enabled him to shed the inertia and stigma of being too closely associated with an increasingly anachronistic style period, while still relying upon certain ideological features of that period as a continuing source of validation. Similarly, in terms of his textual use of genre codes, he roams widely within the genre family of rock, seeming sometimes to stray outside of it altogether, but in a manner which ultimately reasserts rock's centripetal fortitude.

The word I have chosen to describe this doubly paradoxical attitude is waywardness. People may be described as wayward when they follow their own path in a manner contrary to established norms, and perhaps to good judgement. The word is often pejorative, but it is also connected to romantic myths of self-reliance and the exploratory spirit. In terms of Neil Young, the most important connotation is that waywardness explores and celebrates a territory at the same time as it evokes a mode of deterritorialization. I use the word to indicate a habit of wandering broadly, but within the limits of your home territory, allowing you to be both an insider and an outsider, a nomad and a homesteader.

Of course, as Grossberg has noted, a great deal of rock music has traditionally hinged upon affective resistance to boredom and a degree of alienation from hegemonic culture..$^{44}$ I take this to suggest, in part, that restlessness and mobility are core themes in most kinds of rock music, not just in the work of Neil Young. Some of the less unusual features of Young's waywardness include his refusal of external definition, his interest in chaos and disorder, his self-reliance, and his ideology of expressivity. Somewhat more distinctive, but still shared with many rock artists, are his tendency to jump between genres and moods, and his uneasy alliance with corporate cultures. But even where he shares these tendencies with other rock performers, there is a question of degree. Neil Young is wayward with greater intensity and frequency than most other rockers. Also unique is the degree to which Young has allowed these experiments at times to damage his career and put his authorial integrity into question.

Paradoxically, this willingness to risk his credibility became the ground on which Neil Young was constructed as an auteur. Auteurship has been a key trope in ideologies of authenticity and value among rock fans and critics since the mid-1960s. ${ }^{45}$ Neil Young's waywardness, rather than escaping rock ideol-

43 Ibid., 139, 151-52.

44Lawrence Grossberg, Dancing in Spite of Myself: Essays on Popular Culture (London: Duke University Press, 1997), 31-32.

45For more about the place of auteur theory in rock culture and rock criticism, see Roy Shuker, Understanding Popular Music, 111-13, and Will Straw, "Characterizing Rock Music Culture: The Case of Heavy Metal," in On Record (London: Routledge, 1990), 103; article originally published in 1983. 
ogy, is often cast in terms of integrity, self-reliance, and determination, all of which are central to the ideology of auteurship, and to the myth of American individualism that Greil Marcus argues is also central to rock overall. ${ }^{46}$

A wayward life is a kind of mobile habitat, one which both evades and relies upon the territory through which it moves. Neil Young has been maximally wayward within the confines of the rock territory, so much so that for some listeners he has seemed to stray beyond it. If he has appeared unpredictable, it is because few rockers wander so far, and also because some of the subgenres of rock to which Young has wandered are sufficiently marginal that not everyone even thinks of them as part of the family. However, I would suggest that with a larger view, his entire output is constrained within the genre family and ideological framework of rock. By moving in this complex yet bounded manner, Neil Young has achieved a unique result. Few other bodies of work in rock show how so many of the paths that appear to lead outwards in fact turn back on themselves. There are some other rock artists of the 1960s generation, for example the Rolling Stones, whose work, like Young's, illustrates the fine balance between coherence and collapse, and the rich intermusicality, contained within a single genre. However, I would suggest that Young is distinctive in the way he has made this strategy a central part of his persona. If the result has been a fragmentary career, it is largely because Neil Young's work follows the contradictory forces and multiple histories present in rock music. What Dave Marsh has called a lack of commitment is perhaps better understood as a reflection of the impossibility of fixed positions or final conclusions in an inherently dialogic situation. And as Holly George-Warren implicitly points out, Neil Young achieves this quasi-postmodern style of practice without lapsing into cleverness, or abandoning the intuitive directness that can make rock so exciting.

\section{Abstract}

This paper has two aims: (i) to develop a dialogic theory of genre and stylistic reference, especially but not exclusively for application to rock music; and (ii) to offer a detailed reading of genre play and associated issues-instability, authenticity, and unpredictability-in the music of Neil Young. Under this approach authors, performers, styles, and genres are all treated as various forms of persona, allowing for a fully dialogic analysis of their relationships and mutual interpenetrations.

\section{Résumé}

Cet article poursuit un double objectif : i) formuler une théorie dialogique du genre et de la référence stylistique qui soit particulièrement, mais non exclusivement, destinée à la musique rock; et ii) offrir, à l'égard de la musique de Neil

46Greil Marcus, "All This Useless Beauty," in Stars Don't Stand Still in the Sky (New York: New York University Press, 1999), 20-23. 
Young, une lecture détaillée du jeu sur le genre et d'aspects qui lui sont associés, comme l'instabilité, l'authenticité et l'imprévisibilité. Par cette approche, les auteurs, les interprètes, les styles et les genres deviennent tous diverses formes de personnages. Il est ainsi possible d'élaborer une analyse complètement dialogique de leurs relations et interpénétrations. 